\title{
Construction of the New Jiangsu: One Thought of Rule of Law to Promote Prevention of Air Pollution Xuzhou, Jiangsu Province "Bluer Sky" Plan Practice and Thinking
}

\author{
$\mathrm{N}$ an $\mathrm{Nan}^{1,2, a}$ and $\mathrm{Li} \mathrm{Gou}^{1,2, b *}$ \\ $1{ }^{1}$ Schoolof Environment, Xuzhou Institute of Technology, No.2, Lishui Road, Xuzhou Jiangsu \\ 221116, China. \\ ${ }^{2}$ Jiangsu Laboratory of Pollution Control and Resource Reuse, No.2, Lishui Road, Xuzhou Jiangsu \\ 221116, China.
}

a24850282@qq.com , b6651230880@qq.com

Keywords: Constitutionality; Air Pollution Control; System

\begin{abstract}
The constitution of china is experiencing from forming a socialist legal system with Chinese characteristics to build socialist constitutional system with Chinese characteristics, the center is changed from legislation to constitutional implementation. China changed its position from a legal state to a strong constitutional country. The 2015 is China's "First Fear of Deep Reform". It also opens a new era of construction of ecological civilization system and comprehensive development of environmental protection. This is the new beginning, unprecedented in the history, in this moment, to fully develop the constitutional China. Xuzhou Municipal Government attaches great importance to air pollution prevention and control work, "Bluer Sky" plan as the first of a whole of Xuzhou "Five Plan of Action ", it's for three consecutive years from 2013 to be included in the Governmental plan "Three Focal Point and One Big Project". And that it was issued as official documents of the municipality. It includes: Opinions on the work on improving the ambient air quality in urban areas (Xuzhou Governmental Document (2013) 16), Notice on the Implementation of the Implementation Plan of Air Pollution Control Plan in Xuzhou City (Xuzhou Governmental Document (2014) 105), Notice of the Office of the Municipal Government Printing the Solution of the Air Pollution Prevention and Control in 2015 (Xuzhou Governmental Document (2015) 73) and so on. Around the "seven projects", Xuzhou government effectively controls pollution, effectively manage the haze, to promote the "bluer sky" plan, so that a substantial increase in environmental air quality. To solve the air pollution problem in Xuzhou city, we should first of all with the legal thinking to the vision of its position--the rule of law. Direction - then we need to give them a legal mind to guide it-the pattern of the rule of law. Then we are going to solve difficult - areas of emphasis. "Air pollution, contribute to transformation of Xuzhou, let people convenient", and eventually realize the transformation of Xuzhou environmental protection, promoting economic and social development in the new era.
\end{abstract}

\section{Practical Level}

Xuzhou city of Jiangsu Province, according to State and air pollution prevention and control plans, strengthened leadership, strengthened safeguards, focusing on the development of "seven projects", has achieved significant results[1,2]. First, adjust the industrial structure, its transformation and upgrading projects. Second is the main city of the industrial enterprises out of the city and let them into the industrial park. Thirdly, dust of road management site. Finally, motor vehicle pollution control projects. Fifthly, it's public transportation construction projects. Sixth is the phase-out of coal-fired boilers, prohibited straw burning, the engineering of comprehensive utilization of straw. Seventh is monitoring capacity-building project. It effectively ensures the city's air quality monitoring, early warning and targeted to rectify the upgrade. January to June 2015, Xuzhou City, 
the ambient air quality to more than two days for 99 days, excellent rate of $54.7 \%$ over the same period last year increased by 8 days. According to various statistics, the concentrations of $\mathrm{SO}_{2}$ 、 $\mathrm{PM}_{10}$ and $\mathrm{O}_{3-8 \mathrm{~h}}$ were $39 \mu \mathrm{g} / \mathrm{m}^{3}, 135 \mu \mathrm{g} / \mathrm{m}^{3}$ and $99 \mu \mathrm{g} / \mathrm{m}^{3}$ respectively, dropped by $4.9 \%, 3.6 \%$ and $2 \%$ respectively. The $\mathrm{NO}_{2}$ and $\mathrm{CO}$ concentrations were $40 \mu \mathrm{g} / \mathrm{m}^{3}, 1.5 \mu \mathrm{g} / \mathrm{m}^{3}$ respectively, which increased 5.3\%, 15.4\%; PM2.5 concentration of $72 \mu \mathrm{g} / \mathrm{m}^{3}$, which dropped $15.3 \%$, and fell $14.3 \%$ compared with the statistics in 2013, Table1.

Table 1. Table of change of pollutant evaluation index

\begin{tabular}{ccc}
\hline Pollution & $\begin{array}{c}\text { Concentration } \\
{\left[\mu \mathrm{g} / \mathrm{m}^{3}\right]}\end{array}$ & Reduction[\%] \\
\hline $\mathrm{SO}_{2}$ & 39 & 4.9 \\
$\mathrm{PM}_{10}$ & 135 & 3.6 \\
$\mathrm{O}_{3-8 \mathrm{~h}}$ & 99 & 2 \\
$\mathrm{CO}$ & 1.5 & 15.4 \\
$\mathrm{NO}_{2}$ & 40 & 5.3 \\
$\mathrm{PM}_{2.5}$ & 72 & 15.3 \\
\hline
\end{tabular}

\section{Air Pollution Prevention and Control Should Have a Large Field of Vision}

In Xuzhou, the current air pollution problem is a developing issue, and it is also a historical issue. So we should use the historical vision and eyes of development to correctly locate the air pollution problem. Air pollution finally should be solved by developing[3]. It should be through technological innovation, management innovation to achieve sustainable development. The correct development strategy should be based on the actual situation of the city, to grasp the current historical stage[4,5]. We must clearly understand the historical positioning of environmental protection issues, do not be confused, we should pay attention to environmental governance, but not too panic and not be blind anxious[6]. We should trace the source, in the development, especially through the high-end industrial development path to solve environmental problems.

Expand the Atmospheric Particle Source Analysis, to Identify the Culmination of the Formation of Haze. The analysis of atmospheric particulate matter is the qualitative or quantitative relationship between the establishment of pollution sources and ambient air quality to determine the priority order of air pollution control targets[7]. It is the basis of scientific decision-making. The "culprit" of fog haze will not only find the atmospheric particulate matter sources, but also by monitoring the structure of particulate matter changes in the haze work to make evaluation and guidance. Air pollution control needs "symptomatic medicine"[8,9], airborne particle source analysis, revealing the quantitative input response relationship between Xuzhou regional pollution source and air environment, identifying and analyzing the contribution value and sharing rate of each key pollution source, and clarifying the main direction of particulate pollution prevention and control Air quality management, effective development of air particulate pollution prevention and control measures of the premise and basis.

Build Cooperation Platform, Strengthen Cooperation Joint Defense Control. Landscape connected, air connected. Xuzhou geographical location is very special. It connects with Zaozhuang City, Linyi City, Jining City, Huaibei City, Suqian City, and any area of pollution will affect other areas. Xuzhou city surrounded by mountains, but in all directions up the mountain level, the difference is still relatively large. Analysis of the city for many years the prevailing wind direction data we can also find that, in addition to static wind, the city's most wind direction for the east and northeast wind, is conducive to the transport of pollutants to the urban area. May 23 to 24, 2015, the sixth Huaihai Economic Zone, the core area of the city mayor meeting held in Suzhou City, Anhui Province, Xuzhou, Huaibei, Jining, Lianyungang, Suqian, Suzhou, Shangqiu, Zaozhuang eight city leaders attended the meeting The Xuzhou City leaders Wang Hao attended. The meeting adopted the 
"Huaihai Economic Zone in 2015 the core area of integrated construction of key work program", eight cities jointly signed a cooperation agreement. We should take this as an opportunity to establish a platform for cooperation between environmental cities, "shared responsibility, information sharing, consultation and coordination, joint defense control" from the implementation of the paper to a same pollution control line.

In addition, we must base on the "Environmental Protection Law" and "Air Pollution Control Law", to establish Huaihai Economic Zone, the core area of the air pollution control regulations, regional uniform standards, unified law enforcement, in some key high-polluting industries Layout, into the unified management.

\section{Air Pollution Control Requires a Big Pattern}

Xuzhou City, the prevention and control of air pollution from the strategic level to establish a five-in-one "monitoring, governance, prevention, joint, participation" system, five aspects are closely linked, are indispensable, Fig. 1.

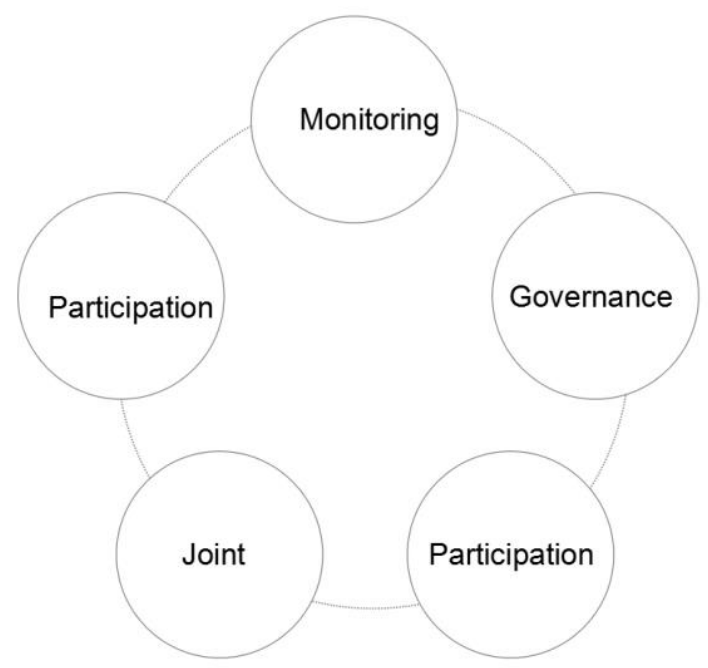

Figure 1. The prevention and control of air pollution

"Monitoring" - enhance the monitoring capacity. Monitoring is a prerequisite for governance. We can only improve the capability of air quality monitoring, so we can accurately find the "root cause." In addition, monitoring should be made available to the public.

"Governance" - tackle the problem. If we find the root cause, we will prescribe the right medicine. Not only "oil - car - road - workers", the government should have a reasonable planning of the city scale, the rational distribution of industrial enterprises, to achieve the total control of pollutants, deepening industrial pollution control.

"Prevention" - the relevant departments should increase the intensity of law enforcement, increase the penalties for violations, the new environmental law "fine base on days" "administrative detention" "seizure seizure" to make serious treatment.

"Joint" - perfect joint defense control. To find out the total emissions in the large area and the number of emissions in each region, to distinguish the regional emission reduction tasks to clear the regional emission reduction responsibilities, strengthen the regional administrative supervision, clear responsibility. Relevant departments should be joint defense control, strengthen environmental protection joint law enforcement. Strengthen the construction of environmental protection team, the establishment of the center of gravity down, the power of the subsidence of the working mechanism, the rational allocation of county and township environmental agencies, they can be listed or other ways in the township (street) to set up a formal environmental agencies, personnel from the township (street) Party committee and government of the existing financial staff in the swap.

"Participation" - emphasize public participation. The "Environmental Participation Approach" 
was approved by the Ministry of Environmental Protection on July 2, 2015 and will come into effect on September 1, 2015. Air pollution prevention and control need science, according to law, more need for universal governance. Need to mobilize all aspects of the power to join the ranks of governance, with the action that Xuzhou people can see the blue sky.

\section{The Management of Air Pollution Should Find Solution, Make Breakthrough and Focus on Key Areas}

The management of Air Pollution Should Find Solution to the Difficulties of Environment and

Development. The management of air pollution should firstly seek for air solution, meaning that we should realize its urgency in history, realizing the urgent situation of air problems. Advocating green development is promoting the coordinated development of economy and environment and solving the problem of lacking of development and resources.

For the policies, firstly the financial aid on clean energy resource consuming policy should be completed. We should concentrate on the relationship between the price of electricity generating and heat generating. Make sure to set a reasonable aid on the prices of electricity and heating and give biological, wind power and solar energy more support. Secondly, the green aid policy should be transferred from the investment to the actual manufacturing and consuming process. In accordance with the cost of pricing methods, sulfide, nitrogen oxides, carbon dioxide emissions of environmental costs and economic costs will be internalized, according to the approved difference in the production and use of clean fuel links to subsidize the green consumer market-orientation, and enhance clean energy Market Competitiveness. Third, government subsidies to agriculture should be inclined to ecological agriculture. Reduce and stop subsidies for pesticides, fertilizers, herbicides, plastic film manufacturers to avoid farmers to destroy agricultural ecological environment.

In terms of funding, firstly, it increases the county transfer payments. By adjusting the structure of optimal expenditure, we can reduce the scale of municipal finance expenditure and concentrate the financial resources to increase the amount of subsidy and special subsidy. In particular, we should make use of the ecological compensation mechanism to ensure the pollution control of the county. Secondly, increase the intensity of competition. Municipal finance, Development and Reform Commission, environmental protection, energy conservation and other relevant departments should actively strive for projects and funds. Thirdly, strengthen the role of financial credit to encourage social capital to participate in pollution control. We should establish environmental information communication mechanism to reduce the "double high" corporate credit support, and strengthen the implementation of green credit policy; increase the environment-friendly industry support, through the bank environmental performance assessment, environmental information disclosure, green credit ranking mechanism and green credit Business tax incentives, etc., to encourage financial institutions to support the development of environmental protection industry; provide financial subsidy credit support for air pollution control projects, enterprise process improvement, energy structure adjustment and clean energy industry, low energy consumption and low emission enterprises. At the same time, update the methods and modes of urban public infrastructure projects such as heating and gas supply, encourage the government and social capital cooperation (PPP mode) to operate, attract social funds to participate in public infrastructure, public service facilities.

Air Pollution Control should Make Break Through to Take Breakthrough Measures. Air pollution control should make break through to take breakthrough measures, mainly by science and technology to lead, strengthening technical support efforts.

Speed up the construction of "wisdom Xuzhou". Learn from the Experience of Intelligent City Construction in Xi'an. Establish five smart management platforms of air pollution management, flood management, soil management, block management and garbage disposition. With big data and cloud computing as the basis, you can integrate all kinds of real-time data, information resources to achieve the city's "five management" management of intelligent induction, digital simulation, crash management. Improve the geographic information system, digital city system to 
provide the "five management" with basic data. Vigorously strengthen the combination of sensor technology and intelligent application, improve all kinds of on-line monitoring system, strengthen the real-time detection of high energy-consuming enterprises, improves the "five management" management efficiency.

Collaborate to promote energy conservation and emission reduction. Speed up the existing residential building heating metering and energy conservation. We should fully implement the heating sub-household measurement, and also the implement heating energy consumption on-line monitoring to promote energy-saving emission reduction. Actively strive for the province's comprehensive demonstration of the modernization of the construction industry model city. According to statistics, industrial housing saves $10 \%$ than the traditional construction of residential construction in the building, saves $80 \%$ of wood, $50 \%$ of water resources, reducing construction energy consumption by nearly $40 \%$. We also want to improve the life of the building, and to promote the construction of 100-year buildings, and to avoid large demolition.

To build a research platform, strengthen the "think tank" construction. It is proposed to jointly establish the Environmental Engineering Research Institute (Institute) by the China University of Mining and Technology, Xuzhou Institute of Technology, etc., and the Municipal Science and Technology Cooperation and Application Research Institute to register as a non-corporate social organization to facilitate the transfer of the results and the purchase of government services[10], and actively do a good job of water, gas, soil pollution control and environmental protection industry development and other research.

Air Pollution Control should Focus on Key Areas.Highlight the key areas of air pollution prevention and control, that is, to focus on the current hot issues to solve the most serious, the most obvious and featured problems which the public most concerned about. So that people in the whole society can feel the improvement of air quality, so as to improve social trust. In the specific work, we should adhere to the coordinated pollution control, focusing on coal control, dust control, vehicles control, capacity, integrated management, legislate these six core pollution control measures. First, control coal. Focus on "governance, control, control" to reduce coal, manage coal quality, vigorously adjust the urban energy structure. Second, to control dust we should establish a cross-joint system of government, university institutes, research institutions, enterprises and legal organizations, cultivate comprehensive technical personnel and team, and build professional organizations with high level of research ability, comprehensive evaluation ability and emergency response capability. Play a leading role in the government to guide the anti-dust products production, particulate matter monitoring links related to the benign development of enterprises, scheduling all aspects of independent innovation and active control of the initiative. Thirdly is vehicle control. For urban road congestion, serious waste gas, pay attention to "car, oil, road" work hard. "Car" aspect, we should eliminate the yellow standard cars and old vehicles, to speed up the promotion of new energy vehicles "Oil" aspect, we should enhance the fuel quality, the city should use the "GUOSI" oil products, to implement the clean energy transformation. Urban buses and taxis all should implement the "oil to gas" transformation, dual fuel vehicles should account for $12.9 \%$ of the city's motor vehicle ownership. In the "road" aspect, we should take the rail transit, city highway, crossing road construction and "Chang jiao tong" projects into practice. We should build a public bicycle rental system covering the urban area and reduce the motor vehicle idling. Fourth is compatibilization. Effectively strengthen the corridor greening, shelter forest construction. Strengthen the management of shelter dust on shelterbelts. In the haze weather, in the shelter belt, we should organize artificial spray shower method to prevent secondary pollution. We should strengthen the three-dimensional greening, enrich the spatial structure of urban landscape and urban landscape art effect, to further increase the amount of urban greening, reduce heat island effect, vacuum, reduce noise and harmful gases, create and improve the urban ecological environment, to build Complete urban ecological network. Fifth, burning is prohibited. We should totally prohibit to burn straw in open area. With the conception of complete usage of straw to propagate "Jie Gan Zhi Yong Wei Bao, Qi Zhi Wei Hai", so as to guide the public to use straw as energy and make full use of it. Sixth is catkin pollution control. The horticultural ministry should pay attention to the research 
of urban Street tree species selection and plant configuration and reduce catkin pollution. First, we should speed up the update. We should update the Poplars in the city which are older than 10. Secondly, we should speed up the production of poplar alternative varieties of seedlings breeding. Finally is drug regulation. According to the survey, Dongcheng District in Beijing carried out Interference agent injection on mature poplars and made some progress [11]. As they are updating the poplars in city, they are also practicing Interference agent injection to control the Amount of knot of certain poplars. Each plant of poplar female will be injected once a year, each injection costs about RMB 30 yuan, the success rate is of $90 \%$ or more. Seventh is legislation. We should, at work, uphold the way of thinking and rule of law in the rule of law, explore the establishment of a system of laws and regulations governing pollution, speed up the process of pollution control according to law, and escort it for scientific pollution control. Accelerate the development of "Xuzhou City, the implementation of air pollution control law approach" and other local air pollution control laws and regulations.

\section{Conclusion}

The greater difficulty is, the closer hope is. Although the current air situation in Xuzhou City is very grim, and before the turning point, this grim situation will continue for a long time. At the same time it also means that the city's air pollution control work has been gradually achieved results, and that we are now step by step practical work will eventually achieve the desired results. In the practice of promoting air pollution prevention and control, we must control haze by science, by law, by firm faith, by joint, to make Xuzhou City better, to promote the work of efforts to make blue sky White clouds become normal.

"Control Haze by Science" is the premise. As a systematic project, air pollution control can't engage in singles one, it must be considered, scientific policy. We must adhere to the pollution control haze and industrial structure adjustment, ease the security smooth, urban meticulous management and ecological engineering construction combined, tackling the problem, highlight the focus, to promote; at the same time, adhere to internal and external cooperation, regional linkage, and actively implement Control Mechanism of Urban Agglomeration in Huaihai Economic Zone.

"Control Haze by Law" is the protection of controlling haze. The government should adhere to the rule of law thinking and the rule of law to promote the control of pollution and haze, in the letter to do a good job with the implementation of relevant laws and regulations at the same time, combined with the actual implementation of Xuzhou series of policy measures and system norms to ensure that air pollution prevention and control work There is law to follow, there are rules to follow, along the path of the rule of law continue to advance.

"Control Haze by Firm Faith" is the key. The relevant departments should insist on the control of the haze of the intensity and effectiveness of the various departments as a test of awareness and execution of the important scale[], and put it into the city's target assessment, its serious monitoring, serious accountability, true record effectiveness.

"Control Haze by Joint" is fundamental. Air pollution control is a war that can't be lost. The government should strengthen the propaganda and guidance, and actively form a strong force of government advocacy, social response, public action, and whole citizen make efforts, everyone involves in this action.

\section{References}

[1] Y. Chen , Probe into Deng Xiaoping's Idea of Sustainable Development. Journal of Shangqiu Teachers College,(3)2005,p.114. (In Chinese)

[2] X.J. Li:Strengthen the Construction of Spiritual Civilization and Promote the Sustainable Development of Our Society (Ph.MS.,Hubei University,China,2004),p.47 (In Chinese)

[3] S.C. Song, A Huge Influence and Vitality of the Theory - Jiang Zemin Discusses the Importance of Comprehensive Development of Socialism with Chinese Characteristics, Dong Yue Trbune,(06)2001,p.7. (In Chinese) 
[4] Y.J. Bai :Study on Deng Xiao-ping's Ideas of Ecological Civilization and Development of Ecological Economy in Shanxi , (Ph.MS.,Shanxi Normal University,China,2014),p.38. (In Chinese)

[5] X.N. Yang ,Analysis of Deng Xiaoping's Sustainable Development, Contemporary World and Socialism,(18)1999,p.86-87. (In Chinese)

[6] Mary Brinton and VictorNee:The New Institutionalism in Sociology.( Stanford:Stanford University Press, America 2001). p.7

[7] Jordan G, Maloney W A and McLaughlin A M. Characterizing Agricultural Policy Making. Public Administration, (72)1994, p.505-526.

[8] Joseph V. Spadaro and Ari Rabl. Air Pollution Damage Estimates: The Cost per Kilogram of Pollutant. International Journal of Risk Assessment and Management . 2002. p.1505-1510.

[9] M Agrawal, B Singh, M Rajput, F Marshall and J.N.B Bell. Effect of Air Pollution On Peri-urban Agriculture: A case Study. Environmental Pollution . (3) 2003. p.55-61.

[10] Y.G. Yue and J.L. Xie, "The battle of linyi" Asks Three Questions, China Environment News,2015. (In Chinese)

[11] Y. Qi, China's low-carbon development report,(China Social Sciences Press,China,2014). 